\title{
Active and Reactive Power Management of Grid Connected Variable Speed Permanent Magnet Generator Wind Turbine
}

\author{
A. E. Haniotis ${ }^{1}$, J. A. Katsigiannis ${ }^{2}$, P. S. Georgilakis ${ }^{2}$ and A. G. Kladas ${ }^{1}$ \\ ${ }^{1}$ Faculty of Electrical and Computer Engineering \\ National Technical University of Athens \\ GR-15780, Athens (Greece) \\ phone: (+30)-210 7723765, fax: (+30)-210 7722336, e-mail: kladasel@central.ntua.gr \\ ${ }^{2}$ Department of Production Engineering and Management \\ University Campus \\ Technical University of Crete \\ GR-73100, Chania (Greece) \\ fax: (+30)- 28210 69410, e-mail: pgeorg@dpem.tuc.gr
}

\begin{abstract}
In this paper a variable speed generating unit is considered, equipped with permanent magnet generator. The system analysis involves appropriate models for the generator, the static converter and the grid. Moreover, an asynchronous generator mounted on the same rotor with dump loads ensures braking actions and management of the active power produced. The modelling of the generator and power electronics interface is presented and checked with measurements realized in a $2 \mathrm{~kW}$ prototype in dynamic conditions.
\end{abstract}

\section{Key words}

Permanent magnet generators, variable speed windturbines, power quality.

\section{Introduction}

The control of variable speed generating systems is a complicated task due to the stochastic nature of available energy e.g. by the wind. Moreover, often conflicting requirements are involved, such as the low cost and reduced stresses [1], on the one hand, and the good output power quality and dynamic characteristics on the other [2],[3].

In this paper variable speed generating units are considered, equipped with permanent magnet generators. The examined generators are multi-polar in order to avoid switch-gears, exhibiting the well-known weight and reliability problems.

In order to achieve variable speed operation, a power electronics converter stage is necessary to connect the generator to the grid [4],[5]. The system analysis in such cases involves models for the generator [6],[7],[8] the static converter [3] and the grid [9].

A $2 \mathrm{~kW}$ prototype of the electrical part of such a variable speed generating unit has been constructed, equipped with a 24 pole permanent magnet synchronous generator
[10],[11]. The modelling of the generator and power electronics interface is presented and checked with measurements realized in the prototype in dynamic conditions.

Measurements as well as control functions are performed by a microprocessor [12]. The simulation and experimental results are used in the development of a low cost $25 \mathrm{~kW}$ generating unit, in the frame of a research project funded by the Greek Secretariat for Research and Technology.

\section{System Modelling}

The basic components of a variable speed wind turbine system are shown in Fig. 1. In this figure, it may be noted that there is no gearbox due to increased reliability purposes. This has been achieved by choosing a convenient multipole permanent magnet generator, in order to obtain low rotor speed. In the case considered 100 poles are needed $(100 \mathrm{rpm})$ for the $25 \mathrm{~kW}$ sized machine while 24 poles $(400 \mathrm{rpm})$ were adopted for the prototype.

The static converter shown in Fig. 1 consists of an uncontrolled 3-phase diode rectifier, a DC/DC boost converter, a 3-phase PWM voltage source inverter and possibly a step-up transformer [13].

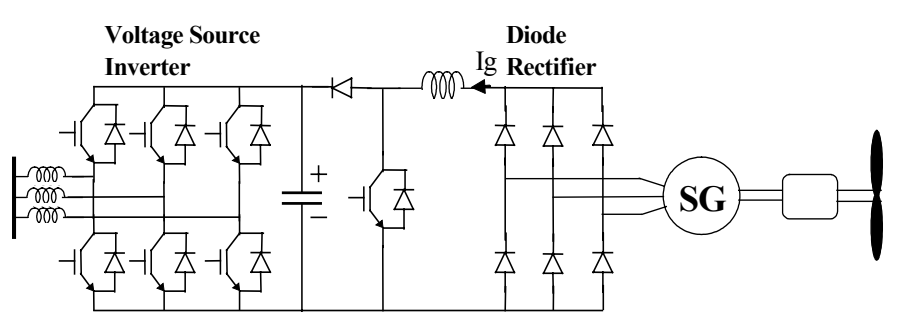

Fig. 1. Subsystems of the electrical part of a typical permanent magnet generator variable speed wind turbine system 


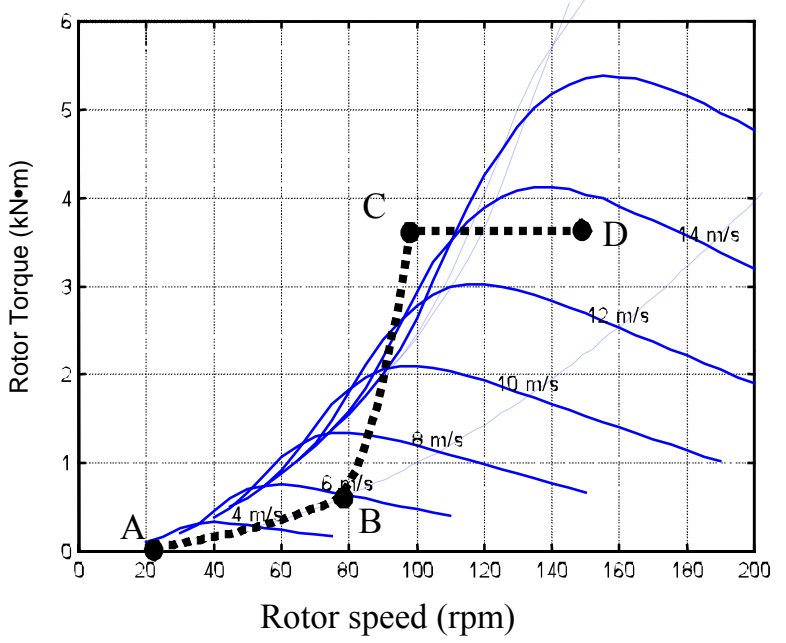

Fig. 2. Aerodynamic part torque-speed characteristics for different wind speeds and proposed control reference

Aerodynamic analysis of the wind turbine blades provided the characteristics shown in Fig. 2. The continuous curves show variations of the rotor torque with rotor speed, for a given wind speed.

The dotted line is the proposed reference for the control system and can be divided into three main parts associated to different control operations: the left-most part, with low inclination, corresponds to the maximum power points for every wind speed. The median part, with high inclination, prevents the turbine from overspeed, thus protecting it by using the stall effect. The right-most part corresponds to the situation that the machine cannot deliver more torque, so an external braking system should ensure over-speed protection in this region. Obviously, the control action should avoid such a situation, that is why the paper is devoted to the implementation of the first two parts of the reference.

The permanent magnet synchronous generator can be represented by a fourth class model which considers as inputs the phase to neutral voltages of the machine as well as the mechanical torque applied to it. The respective equations by using two axes q-d transformation of the electrical quantities can be expressed as follows by using standard symbols:

$$
\begin{aligned}
& \psi_{q s}=\omega_{b} \int\left[v_{q s}+\frac{r_{s}}{X_{l s}}\left(\psi_{m q}-\psi_{q s}\right)-\omega_{r} \psi_{d s}\right] d t \\
& \psi_{d s}=\omega_{b} \int\left[v_{d s}+\frac{r_{s}}{X_{l s}}\left(\psi_{m d}-\psi_{d s}\right)-\omega_{r} \psi_{q s}\right] d t
\end{aligned}
$$

where:

$$
\psi_{m q}=\frac{X_{m q}}{X_{m q}+X_{l s}} \psi_{q s}
$$

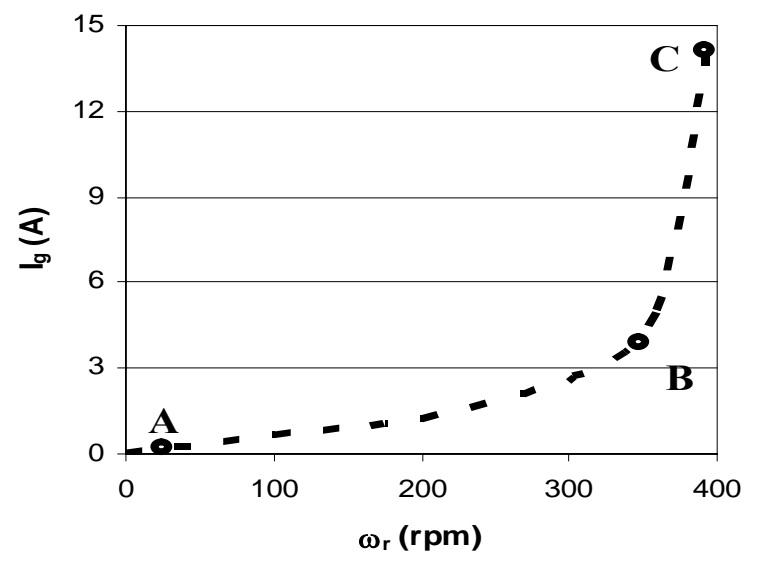

Fig. 3. Proposed Control reference using the rectifier output current with rotor speed characteristic.

$$
\psi_{m d}=\frac{X_{m d}}{X_{m d}+X_{l s}} \psi_{d s}+\frac{X_{m d} X_{l s}}{X_{m d}+X_{l s}} i_{m}^{\prime}
$$

Winding currents:

$$
\begin{aligned}
& i_{q s}=\frac{\psi_{m q}-\psi_{q s}}{X_{l s}} \\
& i_{d s}=\frac{\psi_{m d}-\psi_{d s}}{X_{l s}}
\end{aligned}
$$

Rotor motion equations:

$$
\begin{gathered}
T_{e}=\psi_{d s} i_{q s}-\psi_{q s} i_{d s} \\
\omega_{r}=\frac{1}{2 H} \int\left(T_{m}-T_{e}\right) d t \\
\vartheta_{r}=\omega_{b} \int \omega_{r} d t
\end{gathered}
$$

As electrical quantities can be measured more easily than mechanical ones, an appropriate control technique involves current-speed reference. The current-speed characteristic for the $2,5 \mathrm{~kW}$ prototype corresponding to the torque speed reference shown in Fig. 2 can be determined by using the generator model presented. In such a case the control reference for the rectifier output current with rotor speed is shown in Fig. 3. The first part $\mathrm{AB}$ of this curve corresponds to the maximum power characteristic of the aerodynamic part while the second part $\mathrm{BC}$ represents the over-speed protection.

\section{A. Active Power Control and Braking Capability}

In this work an auxiliary eddy current brake is introduced mounted on the same axis with the generator. As the generator considered is a permanent magnet synchronous machine, braking action can be applied equally in cases of disconnection from the grid (Fig. 4). 


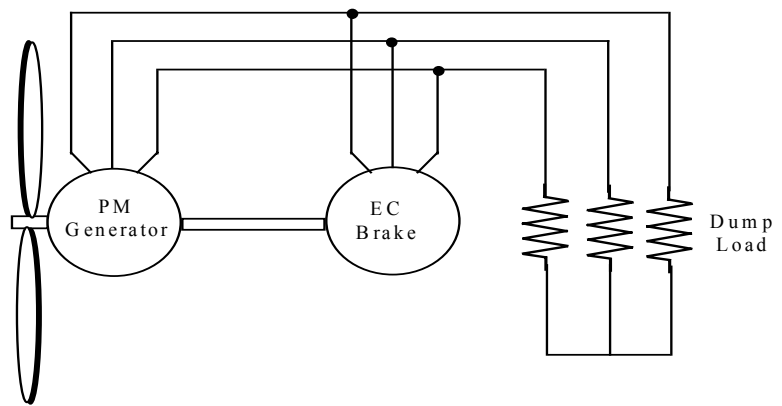

Fig. 4. Configuration of the wind turbine electric part in case of grid disconnection due to fault (PM generator supplying the eddy current brake and the resistive dump load).

The dynamic braking analysis has been simulated by using Matlab/Simulink software.

Both cases of braking of the permanent magnet machine by using dump loads and the parallel operation of the permanent magnet machine with the eddy current brake have been considered. The initial; conditions correspond to a nominal pre-fault generator operation and sudden post fault mechanical rotor increase.

In case of parallel operation of the two machines supplying the dump load connection of appropriate capacitors is also necessary to provide the reactive power absorbed by the eddy current brake. Moreover, the number of poles of the asynchronous brake must be higher than the one of the permanent magnet generator, in order to ensure generating operation for all rotor speeds.

\section{B. Reactive Power Exchange Capability}

The inverter connected to the power grid is simulated in a first step by using the simple representation of a variable load, implemented by switching a fixed resistance. In such a configuration it is essential to conveniently control the parameters of the inverter in order to achieve desired values of active and reactive power flow. The active and reactive power flow per phase (denoted by $\mathrm{P}$ and $\mathrm{Q}$ respectively), through a coupling inductance $\mathrm{L}$, connecting the inverter to a fixed voltage network, can be calculated by using relations (10) and (11):

$$
\begin{gathered}
P=\frac{V_{\alpha} V_{\delta} \sin \delta}{\omega L} \\
Q=-\frac{V_{\delta}{ }^{2}-V_{\alpha} V_{\delta} \cos \delta}{\omega L}
\end{gathered}
$$

where $V_{\alpha}=\frac{M_{f} V_{c}}{\sqrt{2}}$ is the rms value of the inverter output voltage, $\mathrm{M}_{\mathrm{f}}$ is the modulation factor, $\mathrm{V}_{\mathrm{c}}$ the DC link capacitor voltage, $\mathrm{V}_{\delta}$ the rms value of the grid phase voltage and $\delta$ the phase difference between voltage phasors $\mathrm{V}_{\alpha}$ and $\mathrm{V}_{\delta}$.

An important condition for avoiding fluctuating operation is that the capacitor voltage is maintained as steady as possible.

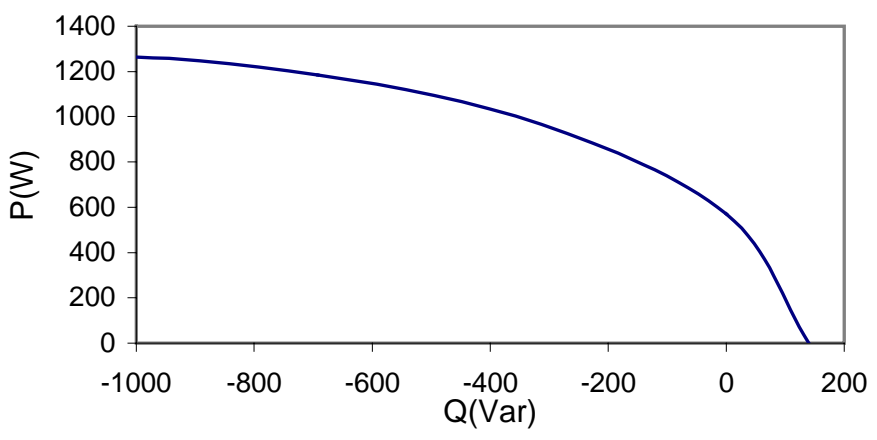

Fig. 5. Operating limits of the per phase active $(\mathrm{P})$ and reactive power (Q) of the inverter

The calculation of the control references to be imposed by the inverter for $\delta$ and $\mathrm{M}_{\mathrm{f}}$ respectively, enabling to obtain desired active and reactive power exchanges, can be performed by the following relations:

$$
\begin{gathered}
\delta=\arctan \left(\frac{P}{Q+\frac{V_{\delta}^{2}}{\omega L}}\right) \\
M_{f}=\sqrt{2} \frac{Q \omega L+V_{\delta}^{2}}{V_{c} V_{\delta} \cos \delta}
\end{gathered}
$$

where $\mathrm{Vc}$ is the capacitor dc voltage, $\omega$ is the base angular frequency and $\mathrm{L}$ is the inductance used for connecting the inverter output to the grid, in the absence of step-up linking transformer.

It may be noted that in the case considered, an inductance $\mathrm{L}=150 \mathrm{mH}$ has been used, in order to limit the current ripple for the switching frequency of $4 \mathrm{kHz}$ adopted.

Figure 5 presents the maximum active and reactive power capabilities of the inverter as calculated by relations (12) and (13) for the adopted value of $\mathrm{L}$. The corresponding variations of the modulation factor $\left(\mathrm{M}_{\mathrm{f}}\right)$ and the phase angle difference $(\delta)$ between voltage phasors $V_{\alpha}$ and $V_{\delta}$ with target per phase active $(\mathrm{P})$ and reactive power $(\mathrm{Q})$ values are shown in Figs. $6 a$ and $6 \mathrm{~b}$, respectively.

\section{Results and Discussion}

In a first step the time responses of open loop and closed loop strategies have been compared. Figs. 7 and 8 compare the time variations of measured and simulated capacitor voltage and rectified current for a torque step from $2 \mathrm{kgm}$ to $3.8 \mathrm{kgm}$ on an open loop with lookup table control system. Although input step is much more intense, it takes only approximately $2 \mathrm{~s}$ to attain the new steady state conditions. The closed loop control system examined adapts to arbitrary changes of the system parts, but is slow in common operation in order to ensure stability. On the contrary, the open loop with lookup 

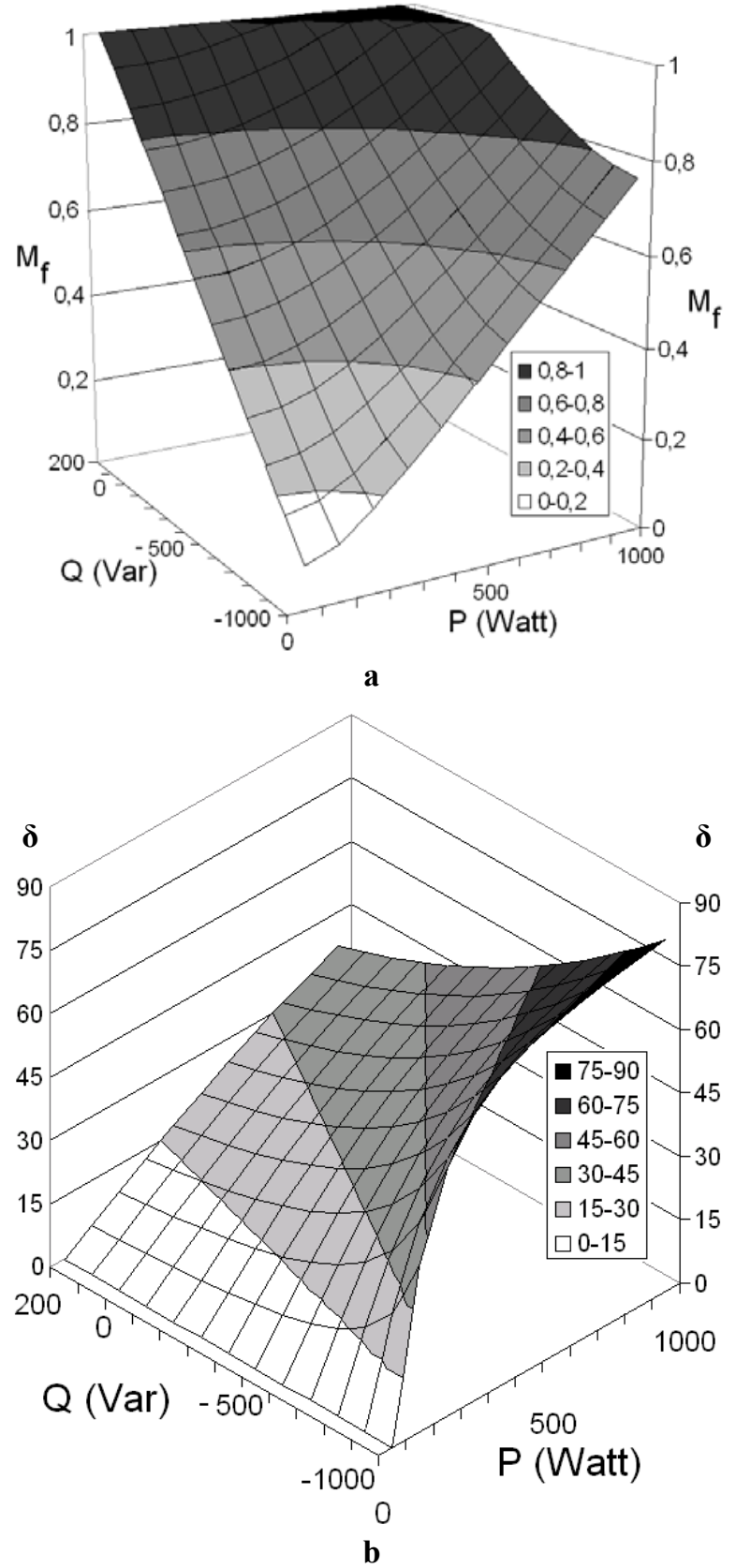

Fig. 6. Parameters variations with target per phase active (P) and reactive power $(\mathrm{Q})$ values.

a: Modulation factor $\left(\mathrm{M}_{\mathrm{f}}\right)$ variation

b: Phase difference $(\delta)$ in degrees between voltages phasors

$$
\mathrm{V}_{\alpha} \text { and } \mathrm{V}_{\delta}
$$

table system examined is three times faster than the closed loop, but cannot adapt to components value variation (Figs. 7 and 8 ).

In a second step the braking capability for different system configurations has been examined. Initial conditions involve nominal wind turbine operation connected to the electrical grid. Then a sudden change in turbine torque has been considered with simultaneous grid disconnection and braking operation by using dump loads (operated at $10 \mathrm{sec}$ in Figs. 9 and 10).

The parallel operation of permanent magnet machine with a copper coated solid iron rotor machine has been

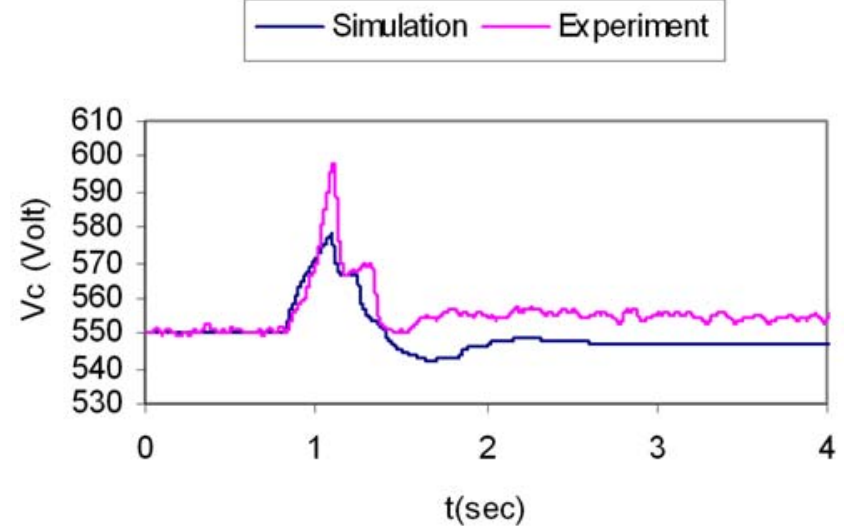

Fig. 7. Time variation of capacitor voltage for input torque step from $2 \mathrm{kgm}$ to $3.8 \mathrm{kgm}$

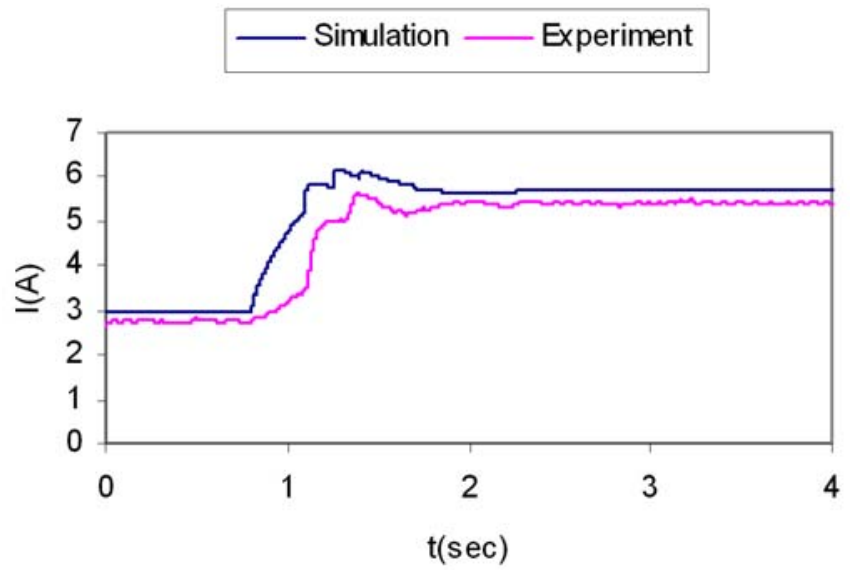

Fig. 8. Time variation of rectified current for input torque step from $2 \mathrm{kgm}$ to $3.8 \mathrm{kgm}$

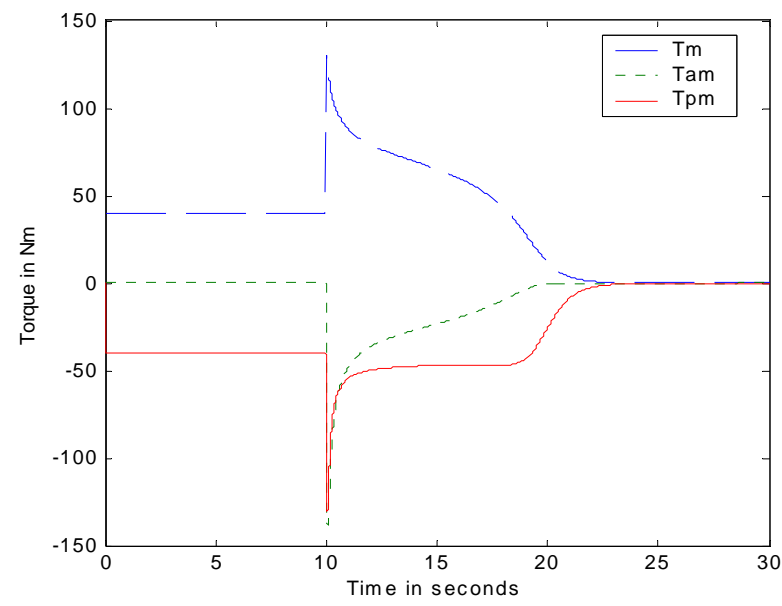

Fig. 9. Braking capability of the parallel connection of the permanent magne machine with the copper coated solid iron rotor brake (mechanical and electromagnetic torque time variations)

considered providing a torque step of $300 \%$ of the nominal torque. The braking characteristics of torque time variations are shown in Fig. 9a while the respective rotor speed time variations are given in Fig. $9 \mathrm{~b}$. 


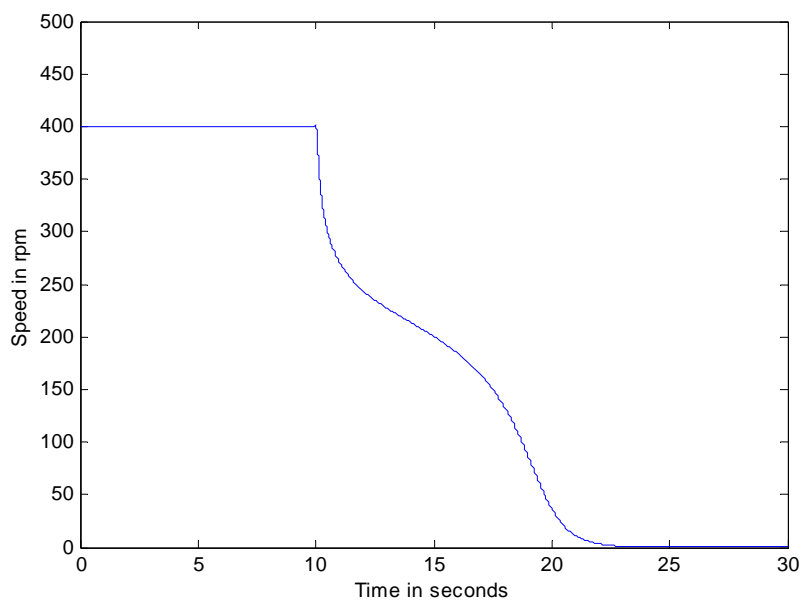

Fig. 10. Braking capability of the parallel connection of the permanent magnet machine with the copper coated solid iron rotor brake (Speed time variation)

experiment

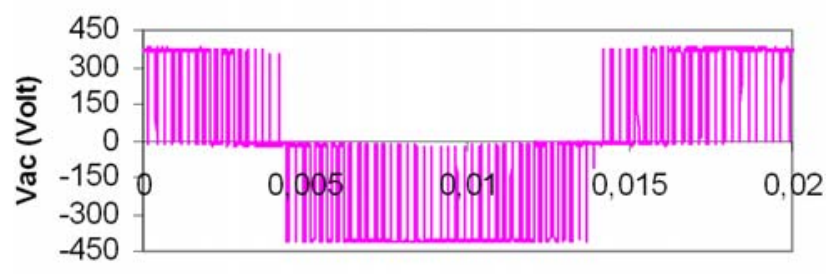

$\mathrm{t}(\mathrm{sec})$

a

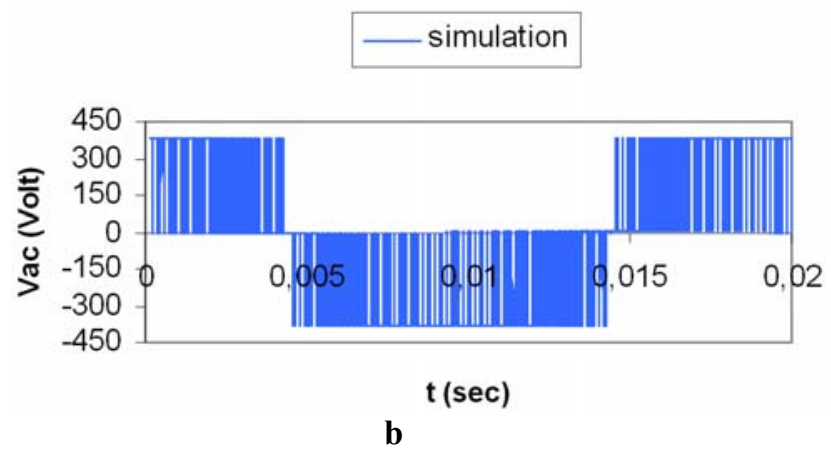

Fig. 11. Waveform of the inverter voltage in case of zero active power generation.

a: experimental results

b: simulated results

In a third step the reactive power exchange capability of the system has been checked. By varying modulation factor Mf and voltage angle $\delta$, the system can control active power flow to the supply grid, as forced by the reference characteristic, as well as reactive power exchange, as defined by the user. Experimental results concerning operating conditions in the vicinity of theoretical limits are given in Figs. 11 and 12.
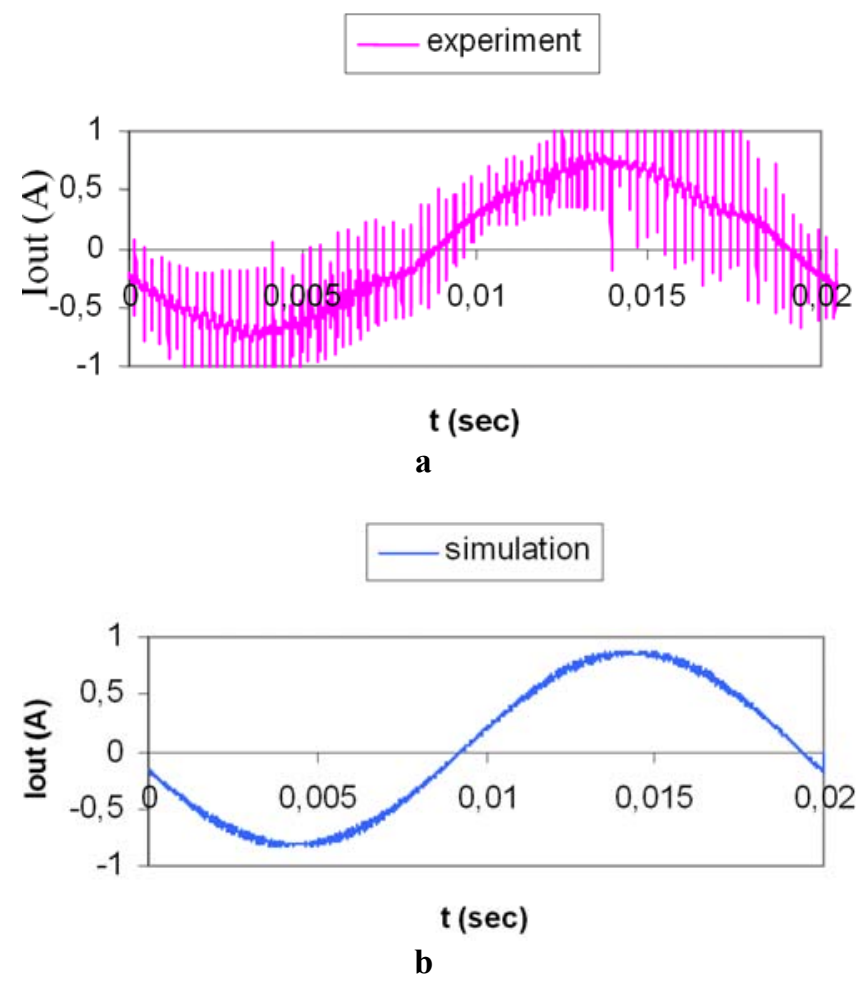

Fig. 12. Waveform of the inverter voltage in case of zero active power generation.

a: experimental results

b: simulated results

Figs. 11 and 12 compare the experimental and simulated waveforms of the inverter output voltage and output current for zero active power generation $(Q=125 \mathrm{VAr})$. Such a condition is achieved by setting the phase angle of the inverter to zero. The corresponding reactive power can be estimated by using equation (14), where $\cos \delta=1$.

\section{Conclusion}

The paper presents modelling and dynamic behaviour investigation of the electrical part of a grid connected variable speed wind turbine equipped with a permanent magnet synchronous generator. Two different control strategies for a variable speed permanent magnet generator have been compared. Such techniques ensure produced power optimization as well as over-speed protection in case of high wind speeds. The relative advantages have been checked by means of a $2 \mathrm{~kW}$ experimental set-up. The proposed system capability to provide reactive power exchanges has also been analysed. The simulation and experimental results are used in the development of a $25 \mathrm{~kW}$ windturbine, in the frame of a research project.

\section{Acknowledgement}

The authors express their gratitude to the General Secretariat for Research and Technology of Greece for the support of this work under Grant 96SYN24. 


\section{References}

[1] M. G. Simoes, B. K. Bose, R. J. Spiegel, "Design and performance evaluation of a fuzzy-logic-based variable-speed wind generation system", IEEE Trans. on Industry Applications, Vol. 33, no 4, 1997, pp. 956-965.

[2] A. J. G. Westlake, J. R. Burnby, E. Spooner, "Damping of power-angle oscillations of a permanent magnet synchronous generator with particular reference to wind power applications", IEE Proceedings - Electric Power Applications, Vol. 143, No 3, 1996, pp. 269-280.

[3] D. J. Leith, W. E. Leithead, "Implementation of windturbine controllers", International Journal on Control, Vol. 66, no 3, 1997, pp. 349-380.

[4] T. M. Jahns, "Motion control with permanent magnet AC machines", IEEE Proceedings, Vol. 82, No 8, 1994, pp. 1241-1252.

[5] N. Mohan, T. M. Undeland, W. P. Robbins, Power Electronics-Converters, Applications and Design, Wiley, 1995.

[6] M.A. Alahmadi, N. A. Demerdash, "Modeling and experimental verification of the performance of a skew mounted permanent magnet brushless dc motor drive with parameters computed from 3D-FE magnetic field solutions", IEEE Trans. on Energy Conversion, Vol. 9, no 1, 1994, pp. 26-35.
[7] F. Colamartino, C. Marchand, A. Razek, "Torque ripple minimization in permanent magnet synchronous servodrive", IEEE Trans. on Energy Conversion, Vol. 14, 1999, pp. 616 - 621.

[8] T. Higuchi, J. Oyama, E. Yamada, E. Chiricozzi, F. Parasiliti, M. Villani, "Optimization procedure of surface permanent magnet synchronous motors", IEEE Trans. on Magnetics, Vol. 33, no 2, 1997, pp. 1943-6.

[9] S. Heier, Grid Integration of Wind Energy Conversion Systems, Wiley, 1998.

[10] D. Aliprantis, S. Papathanassiou, M. Papadopoulos, A. Kladas, "Modeling and control of a variable-speed wind turbine equipped with permanent magnet synchronous generator", ICEM'2000, Helsinki, Finland, August 2000, pp. 558-562.

[11] G. Tsekouras, S. Kiartzis , A. Kladas, J. Tegopoulos, "Neural Network Approach compared to Sensitivity Analysis based on Finite Element Technique for Optimization of Permanent Magnet Generators", IEEE Trans. on Magnetics, Vol. 37, no 5/1, 2001, pp. 3618-3621.

[12] MICROCHIP: Complete PIC18C Reference Manual, 2001.

[13] S. Papathanassiou, M. Papadopoulos, "Dynamic Behavior of Variable Speed Wind Turbines under Stochastic Wind", IEEE Trans. on Energy Conversion, Vol. 14, No. 4, Dec. 1999, pp. 16171623. 